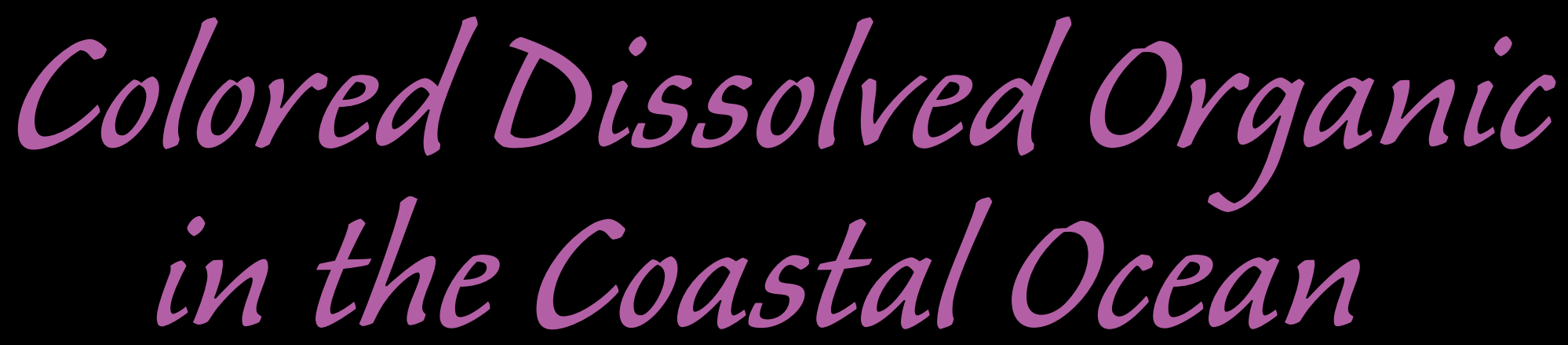

AN OPTICAL TOOL FOR COASTAL ZONE ENVIRONMENTAL ASSESSMENTAND MANAGEMENT

BY PAULA COBLE, CHUANMIN HU, RICHARD W. GOULD, JR.,

GRACE CHANG, AND A. MICHELLE WOOD
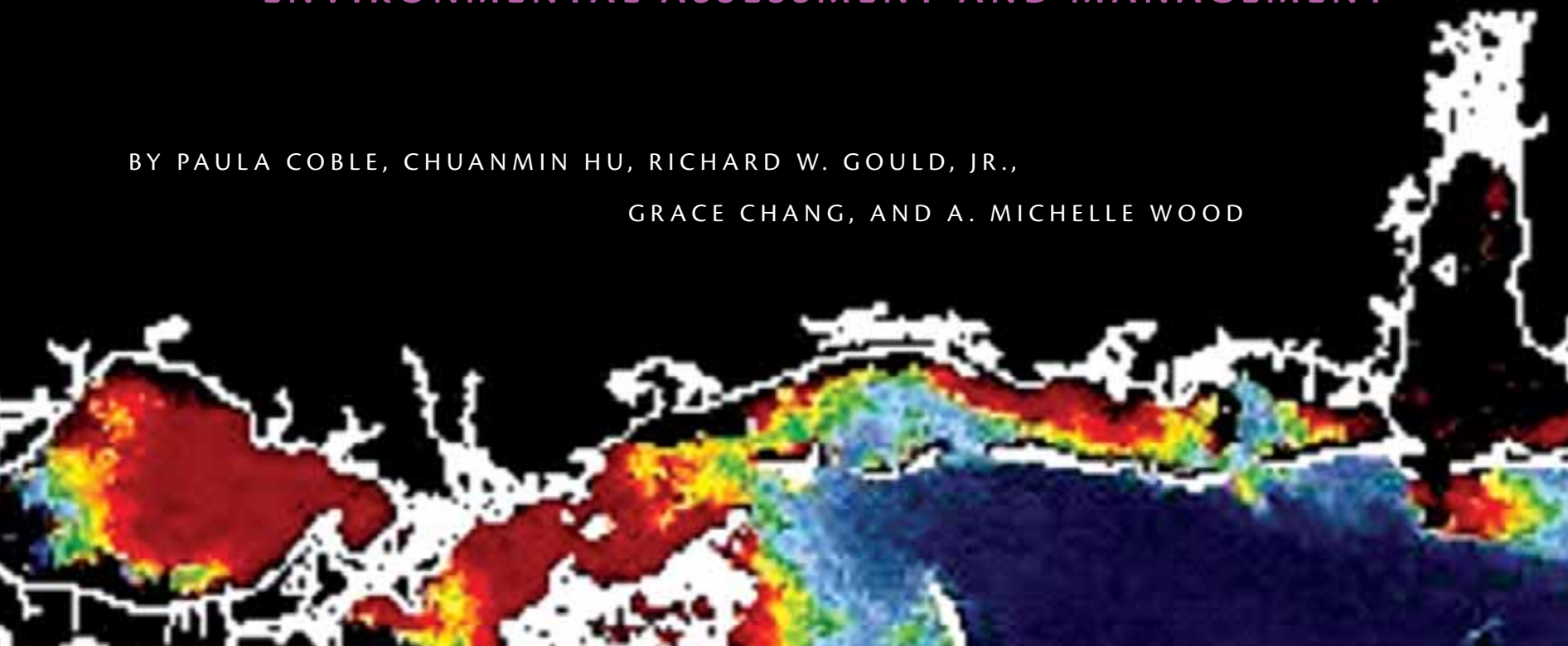

ancosis is

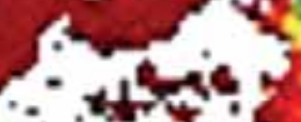

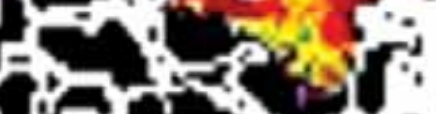

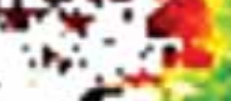

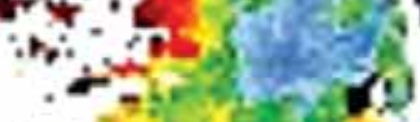

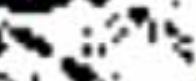

${ }^{+} \operatorname{sen}^{2}$

1, his:

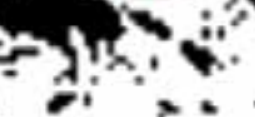

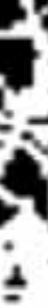

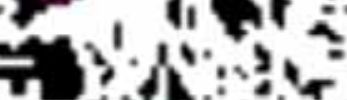

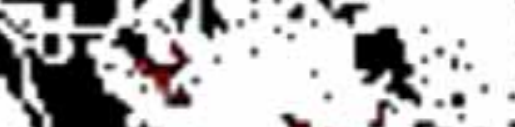

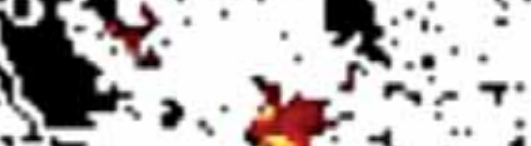

汶.

tis

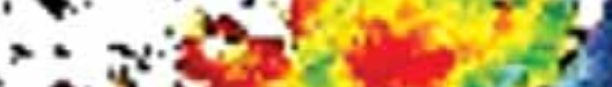

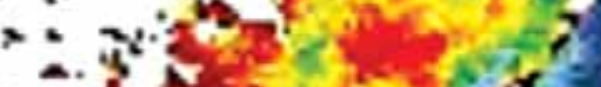

$i x=7$

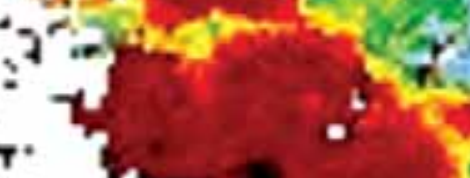

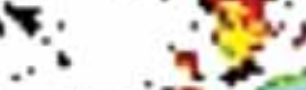

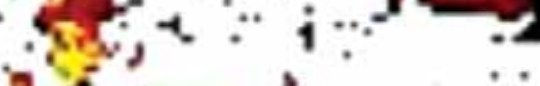
$x^{2}+20$, $\%$ of

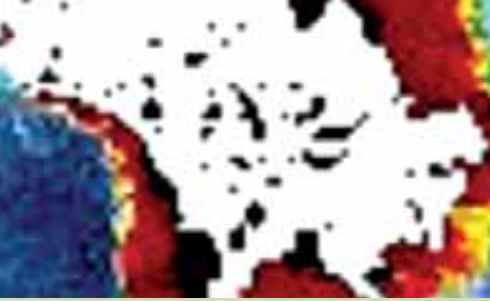



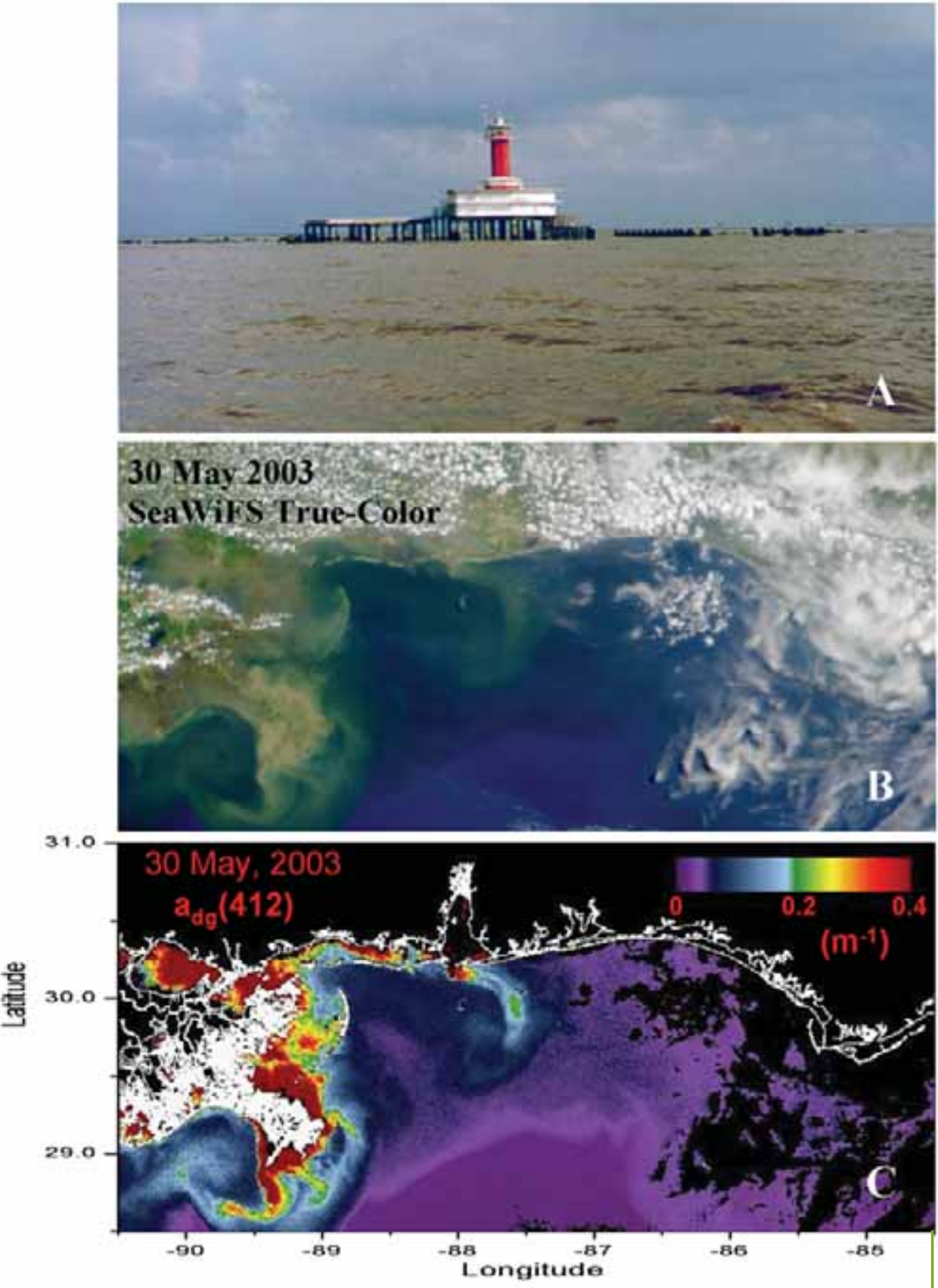

Figure 1. The Mississippi River provides a classic example of a highly colored river. Its large freshwater discharge, and its impact on the Gulf of Mexico are readily apparent in these three views of the river plume (see panels A, B, and C). One image is taken from a boat, the other two are taken from a satellite in space. (A) This photo of the lighthouse at the entrance to the main channel of the river clearly shows how the Mississippi River got is nickname "Muddy Miss." The café au lait color is due to a combination of all components of ocean color. However, despite the presence of plant pigments, the dominant color is due to high turbidity. Levels of CDOM in the Mississippi River are actually low in comparison to levels in other rivers discharging in the eastern Gulf of Mexico.

(B) This image from the SeaWIFS sensor was taken May 30, 2003 and shows the true color an observer would see from space. The café au lait color is easily seen, and extends outward from the river mouth. Lighter shades of this color are caused by dilution of the river plume with seawater, and by sedimentation of the particulate load carried by the river water. Offshore of the brown river

water is a zone of water with a more greenish tinge that contains phytoplankton, now not obscured by sediment particles and stimulated to grow by the dissolved nutrients brought into the coastal zone by the river. The very blue water offshore contains few particles or organic matter of any kind. The waters of the open Gulf of Mexico are as clean and blue as those found in any open-ocean area. This color is much like what one would observe from the deck of a ship, and truly represents the "deep blue sea." The white areas are clouds. (C) Processing the same SeaWIFS image shown in B to represent combined concentrations of detrital and colored dissolved organic matter (CDOM) in the water results in this false color image. The data shown are calculated

absorption coefficients at $412 \mathrm{~nm}$ per meter $\left(\mathrm{a}_{\mathrm{dg}}(412) \mathrm{m}^{-1}\right)$ of water. The distribution of high concentrations of CDOM closely mirrors that of the brown water in B, but not exactly. Note especially the very low CDOM levels that are observed in the greenish

blue regions of $B$. Areas of clouds in this image are shown as black to indicate that data in those pixels cannot be processed. solved organic matter (CDOM). Coastal areas typically have higher and more variable concentrations of these materials than openocean regions, resulting in a more complex optical regime near shore.

In this article, we focus on the properties, sources, sinks, measurement techniques, and distribution patterns of the major dissolved component of ocean color-CDOM. Through an understanding of the complex characteristics and environmental interactions of the CDOM pool, we can gain valuable insight into a variety of physical and biogeochemical processes occurring in coastal and shelf regions.

\section{WHAT IS CDOM AND WHERE DOES IT COME FROM?}

$\mathrm{CDOM}$ is a mixture of compounds that are by products of plant and animal decomposition, and can come from both terrestrial and marine sources. When present in high concentrations, it imparts a brown or yellowish color to water. In coastal areas, most of the CDOM comes from rivers containing organic materials leached from soils. Figure 1 shows two views of the Mississippi River just offshore of where it enters the Gulf of Mexico. The brown color observed from a

Paula Coble (pcoble@marine.usf.edu) is Associate Professor, College of Marine Science, University of South Florida, St. Petersburg, FL. Chuanmin $\mathrm{Hu}$ is Research Assistant Professor, College of Marine Science, University of South Florida, St. Petersburg, FL. Richard W. Gould, Jr. is Head, Ocean Optics Center, Naval Research Laboratory, Stennis Space Center, MS. Grace Chang is Assistant Researcher, Ocean Physics Laboratory, University of California, Santa Barbara, Goleta, CA. A. Michelle Wood is Associate Professor of Biology, University of Oregon, Eugene, OR. 
boat or from the coastline (Figure 1A) is intense enough to also be visible in satellite images (Figure 1B) at certain times of the year. Some of the variation in the shade of brown is due to suspended particles that scatter light, giving the brown water it's "café au lait" color.

In addition to rivers, CDOM is also produced in the ocean by release of organic molecules from organisms during bacterial and viral lysis (cell breakage), excretion, and grazing (Coble et al., 1998; Nelson et al., 1998; Steinberg et al., 2000). Openocean surface waters often show a depletion of CDOM because of sunlight bleaching (Chen and Bada, 1992; Coble et al., 1998; Twardowski and Donaghay, 2002).

\section{WHY IS CDOM IMPORTANT?}

The organic compounds that comprise CDOM are naturally occurring and have a high reactivity with some ions in water. This reactivity leads to a variety of positive and negative effects on humans and the environment. CDOM in drinking-water sources can react with the chlorine added by water treatment plants to form harmful disinfection by products. It can also reduce dissolved oxygen concentrations in natural waters, causing release of nutrients (Bushaw et al., 1996) and some metals from sediments. This nutrient and metal release can result in contamination of water supplies or in negative impacts to aquatic fauna in the environment. Conversely, CDOM is a very good scavenger of compounds like trace metals and polyaromatic hydrocarbons (PAHs), removing them from solution and thereby decreasing their toxicity to organisms.

CDOM reactivity is increased in the presence of sunlight, and CDOM acts as a catalyst for destruction of non-colored compounds, such as organic pollutants. Ultraviolet radiation destroys CDOM and thus is sometimes used in purification of drinking water. Interactions between sunlight and CDOM also have consequences for the environment. The CDOM itself is eventually destroyed by sunlight (Kieber and Mopper, 1987), but this process releases organic compounds (Miller and Moran, 1997) that are required for growth of some phytoplankton and bacteria. Other essential elements, such as nitrogen and trace metals, are also released. Photoproduction of Dissolved Inorganic Carbon (DIC) and minerals provides another pathway in carbon cycling in addition to primary production (see review by Moran and Zepp, 1997). In some cases CDOM acts as a sunscreen, by strongly absorbing UV light, protecting delicate benthic habitats such as those in the Florida National Marine Sanctuary (Williams, 2002). Thus, CDOM plays an important role in carbon cycling and in the biogeochemistry of coastal waters. Changes in the concentration and properties of CDOM in coastal regions can be used to trace physical circulation and water-mass history. This information can be useful in tracking freshwater plumes to assess the impact of river-borne components, such as nutrients and pollutants, that may impact fisheries and water quality. It can also help scientists better understand complex circulation patterns and dynamics in coastal regions.

\section{HOW IS CDOM MEASURED?}

The precise composition of CDOM remains undetermined, therefore its concentration cannot be measured in terms of number of molecules per volume solution. It is de- fined and measured based on the intensity of absorption of light or fluorescence emission. Both fluorescence and absorption of CDOM vary as a function of wavelength and source of CDOM, therefore, the wavelength at which measurements are made must be specified. In fact, spectral measurements of CDOM absorption and fluorescence provide useful information on CDOM source and have been used to study water-mass mixing in the ocean (Coble et al., 1998; Blough and Del Vecchio, 2002).

Optical instrumentation is used to measure CDOM in water samples both in the laboratory and in situ using absorption and fluorescence techniques. Instruments can be deployed on a variety of sensor platforms (e.g., shipboard profilers and towed underway bodies, moorings, autonomous underwater vehicles) to record high spatial and/or temporal in situ measurements of CDOM. Spectral fluorometers can measure CDOM concentration directly in the presence of plant pigments by isolating excitation and emission wavelengths specific to CDOM. Absorbance measurements, however, are not as discriminating. Spectral absorption meters equipped with pre-filters can be used to directly measure CDOM contribution; however, the problem is more difficult in situations when particles cannot be removed. The absorption bands of the colored components overlap, so spectral interpretation requires models and algorithms that assign absorption to different components (see Schofield et al., submitted and references therein) to estimate the contribution of CDOM, phytoplankton, and non-living detrital matter to total absorption.

Ship and mooring measurements provide only limited spatial coverage, however, 
and cannot adequately resolve the dynamic coastal variability of processes driving CDOM distribution patterns. To resolve this spatial variability, synoptic satellite estimates are required.

Satellites do not measure absorption, but rather measure reflectance, or water-leaving radiance exiting the ocean surface. Reflectance is sunlight leaving the surface of the ocean that has not been absorbed or scattered by seawater components, and its color is indicative of the amount of, for example,
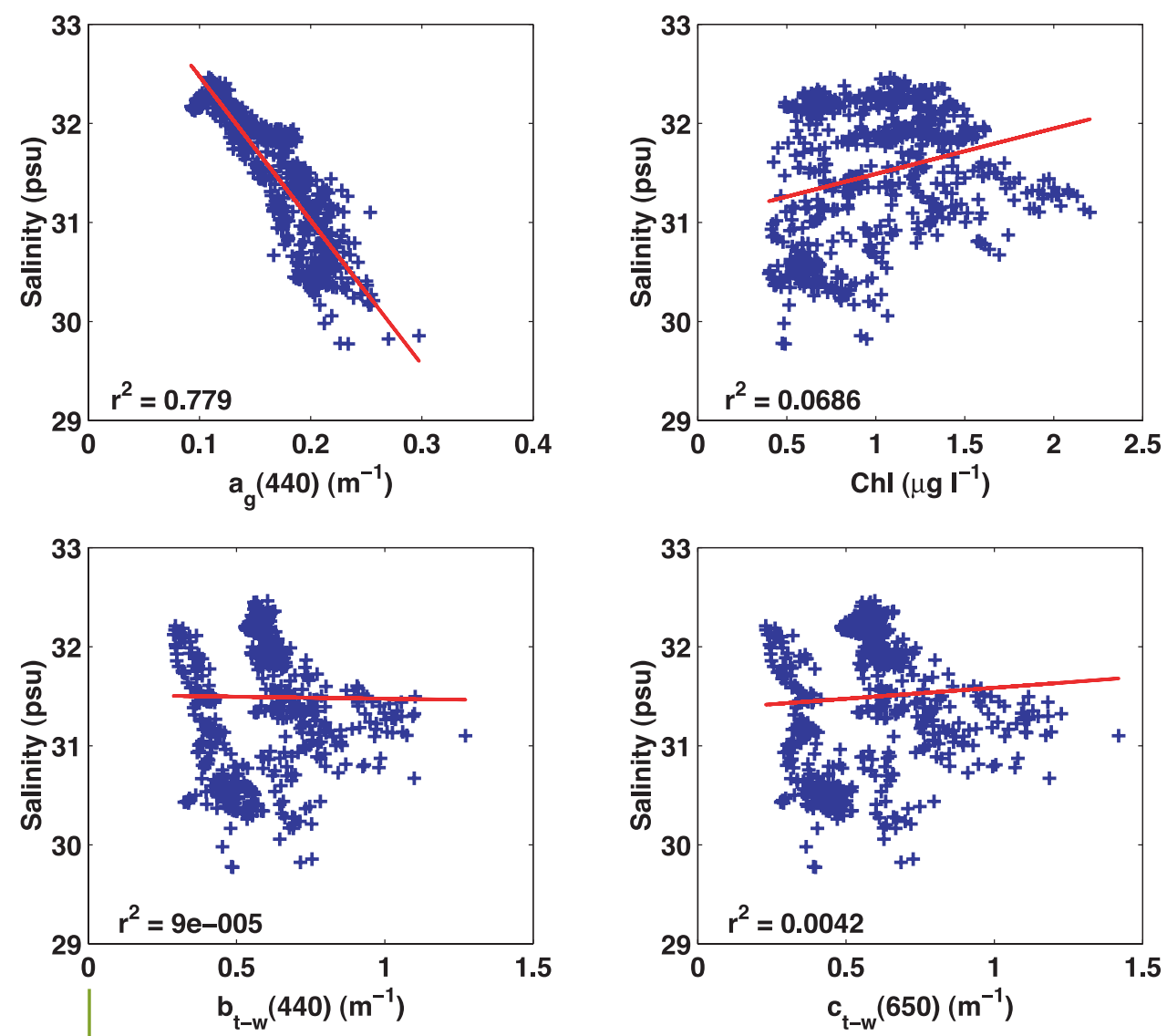

Figure 2. Although ocean color is due to chlorophyll, particle absorption and scatter, and CDOM, only CDOM has value as a tracer of freshwater input in most coastal regions. This is because rivers are the primary source of CDOM, while chlorophyll and particles can have other sources. When simultaneous measurements of salinity and ocean-color parameters are made, only salinity shows a linear relationship with CDOM (top left), in this case measured as absorption at $440 \mathrm{~nm}$ $\left(\mathrm{a}_{\mathrm{g}}(440) \mathrm{m}^{-1}\right)$. No significant relationship is usually observed between salinity and chlorophyll (top right), or between salinity and particle concentration, in this case as measured by backscatter (bottom left) and beam attenuation coefficient (bottom right). Pigment concentrations change with nutrients and sunlight, increasing or decreasing with the biological response of the phytoplankton to the chemical and physical factors of the environment. Sediments can be stirred up from the bottom in shallow coastal areas irrespective of the load delivered by the river, and settle to the bottom when water velocities slow, independent of dilution with seawater. development and validation of satellite algorithms. A variety of algorithms have been developed in recent years, and each has advantages and drawbacks. Further details of algorithm development and application are provided in other articles in this issue (see Chang et al., this issue; Schofield et al., this issue).

Daily satellite measurements of ocean color using the SeaWiFS (Sea-viewing Wide Field-of-view Sensor), MODIS (Moderate Resolution Imaging Spectroradiometer), and MERIS (Medium Resolution Imaging Spectrometer) allow observation of CDOM distributions for periods of days to weeks (or longer) at $1 \mathrm{~km}$ spatial resolution. Hence, the satellite estimates can be used to optically track water masses and features at time scales comparable to the processes controlling the distribution patterns (mixing, photo-bleaching, phytoplankton growth, advection, particle settling, and resuspension; see Arnone et al., this volume). Due to the optical complexity in coastal waters, satellite data need to be verified and calculations adjusted based on analysis of water samples from the area of interest.

\section{WHY IS CDOM A GOOD TRACER?}

Because rivers are the main source of CDOM in coastal regions, we often find an inverse correlation between CDOM concentration and salinity-CDOM is high where salinity is low (Blough and Del Vecchio, 2002). Chlorophyll concentration usually is not correlated with salinity or CDOM in these regions. Figure 2 shows relationships between salinity and the major ocean color parameters-CDOM, chlorophyll, and particles. Data were collected at $5 \mathrm{~m}$ by the Ocean Physics Laboratory (OPL) HyCODE mooring, which was deployed about $25 \mathrm{~km}$ offshore of Tuckerton, New Jersey, at a water depth of $24 \mathrm{~m}$, from May 17 to June 13, 
A case of elevated CDOM concentration (absorption) in coastal oceans resulted in the 2002 "black water" near the Florida Keys (panels A, B,

$C$ to the left), which was found to be a mixture of an earlier red tide bloom and local river runoff (SWFDOG, 2002). The SeaWiFS true color composite image (panel A) shows a large patch of dark water north of the Florida Keys, which was referred to as "black water" by the general public. The color is the result of backscattering from suspended particles and water molecules in combination with absorption by CDOM, phytoplankton, water molecules, and other suspended materials. The relative amounts of each component can be estimated from the total ocean-color signal by using bio-optical algorithms, such as a recently developed optimization approach (Lee et al., 1999; Hu et al., 2003). The CDOM absorption image in panel $B$ shows elevated CDOM values (see green, yellow and red areas) downstream of the Everglades rivers, indicating that coastal runoff at least partially contributes to the "black water" event. The magnitude of CDOM absorption ( $440 \mathrm{~nm}$ ) in the "black water" patch is about $0.1-0.3 \mathrm{~m}^{-1}$, confirmed by a field survey performed later (Jennifer Cannizzaro, University of South Florida, St. Petersburg, pers. comm.) Accompanying the high CDOM concentration, the coastal runoff also carries high concentrations of nutrients that may have stimulated a diatom bloom found in the "black water" patch. This example demonstrates that $\mathrm{CDOM}$ can be used effectively to trace the water origin, and thus is a useful tool for coastal resource management.

SeaWiFS images show "black water" north of the Florida Keys on February 18, 2002. (A) True color composite image; (B) CDOM absorption ( $440 \mathrm{~nm}$ );

(C) Particle backscattering $(400 \mathrm{~nm})$. Absorption and backscattering images were obtained from SeaWiFS water-leaving radiance data with a spectramatching optimization algorithm (Lee et al., 1999; Hu et al., 2003).
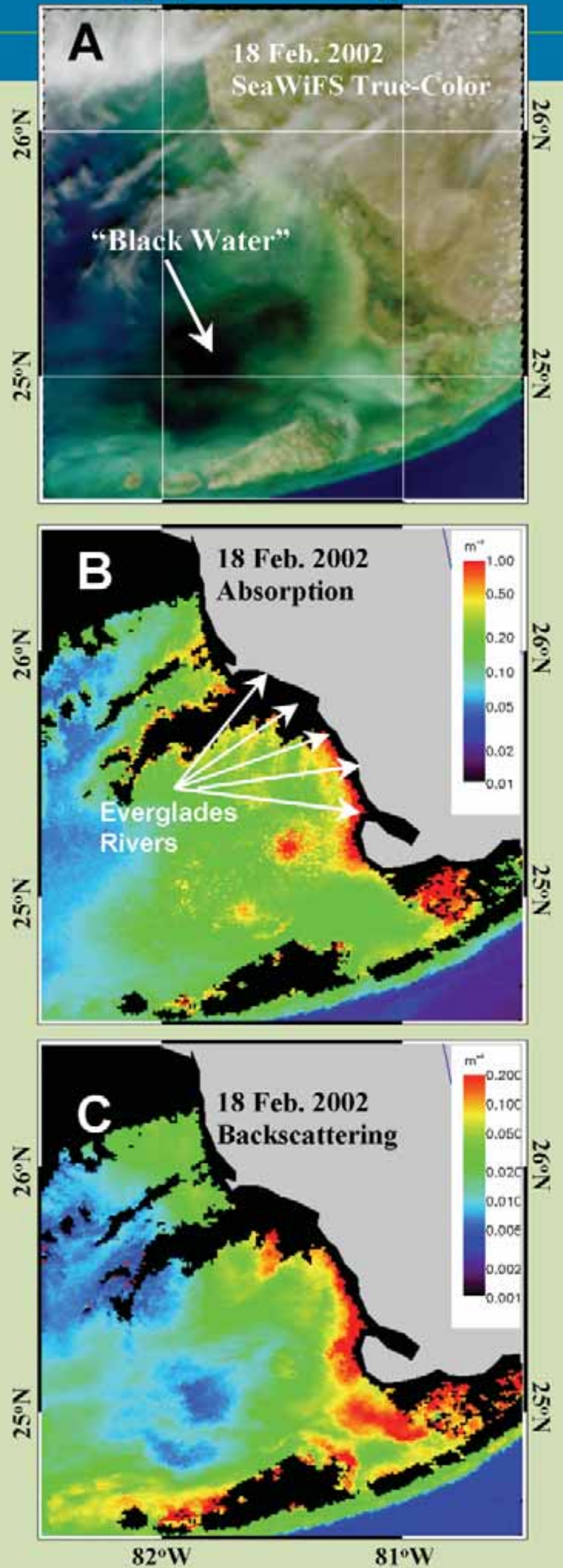
2000. These data show that CDOM absorption is the only bio-optical property that is significantly correlated with salinity. $\mathrm{R}^{2}$ values for chlorophyll concentration, total scattering (b), and total attenuation (c) with salinity are close to zero, compared to the 0.77 value for CDOM.

The relationship between salinity and CDOM means that ocean-color satellite images can be used to map freshwater intrusions into the coastal ocean, reflecting changes in river discharge rates as well as variations in CDOM from different rivers within a given coastal region. Both salinity and CDOM can act as passive tracers as the coastal waters diffuse and mix with the higher-salinity, lower-CDOM offshore waters. The CDOM signature varies through time, however, due to photo-bleaching effects, so it should only be considered a "pseudo-conservative" tracer. An example of one such map is shown in Figure 3 for the northern Adriatic Sea in February 2003. In this study, salinity and CDOM data were collected using a continuous, underway, flow-through measurement package. Note that in offshore areas away from the influence of the Po River discharge, the relationship is weaker or nonexistent (blue points along cruise track and in scatter plot). This is due to long exposure of CDOM at the surface to sunlight, which destroys the inverse correlation with salinity. Thus, the relationship between CDOM and salinity is temporally and spatially variable. It depends on the mixing of river and marine waters and on the CDOM source. Different rivers have varying composition and concentrations, and marine CDOM is compositionally different than riverine CDOM.

In coastal regions lacking a strong river input, the highest concentrations of CDOM are found in subsurface waters, below the limit of light penetration. In areas where upwelling occurs, this can cause the relationship between CDOM and salinity to be reversed, such that CDOM is high at higher salinities. Figure 4 shows one example from Monterey Bay, California during a period of strong northwesterly winds (April 2003). The data points at salinity values higher than 33.2 represent the most recently upwelled waters. Data at lower salinities show the influence of mixing with fresh water and photobleaching as upwelled water persists at the surface.

\section{WHAT IMPACT DOES CDOM HAVE ON THE ECOSYSTEM?}

Some types of phytoplankton appear to preferentially thrive where CDOM concentrations are elevated above seawater levels. This could be due to a variety of factors. Input of CDOM to coastal waters, whether
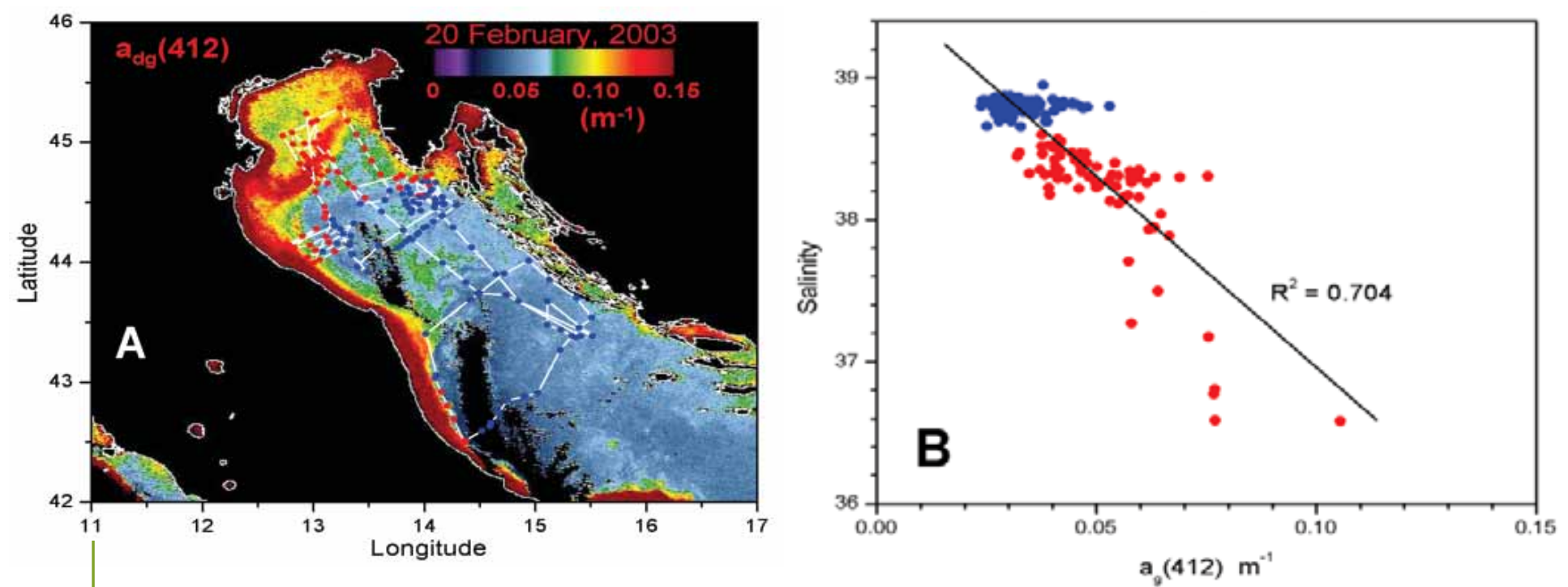

Figure 3. In areas where a strong relationship between salinity and CDOM has been established, satellite images of CDOM concentrations can be interpreted as indicative of freshwater distribution. One such area is in the Northern Adriatic Sea. In (A) the cruise track (in white) from February 3-21, 2003, is overlaid on a SeaWiFS CDOM ( $\mathrm{d}_{\mathrm{dg}}(\mathrm{4} 12) \mathrm{m}^{-1}$ ) image from February 20, 2003. Continuous underway flow-through measurements were made of salinity and CDOM collected with a $0.2 \mu \mathrm{m}$-filtered ac9 instrument. CDOM absorption intensities are indicated by blue (low) and red (high) dots along the cruise track. (B). These same CDOM data ( $\mathrm{a}_{\mathrm{dg}}$ at $412 \mathrm{~nm}$ ) are plotted vs. salinity. Symbol colors correspond in A and B. Red points were measured in coastal locations where salinity and $\mathrm{a}_{\mathrm{g}}$ are inversely related; blue points are from more offshore locations, show no relationship. In offshore regions, CDOM can be destroyed by exposure to sunlight and other degradation processes. 

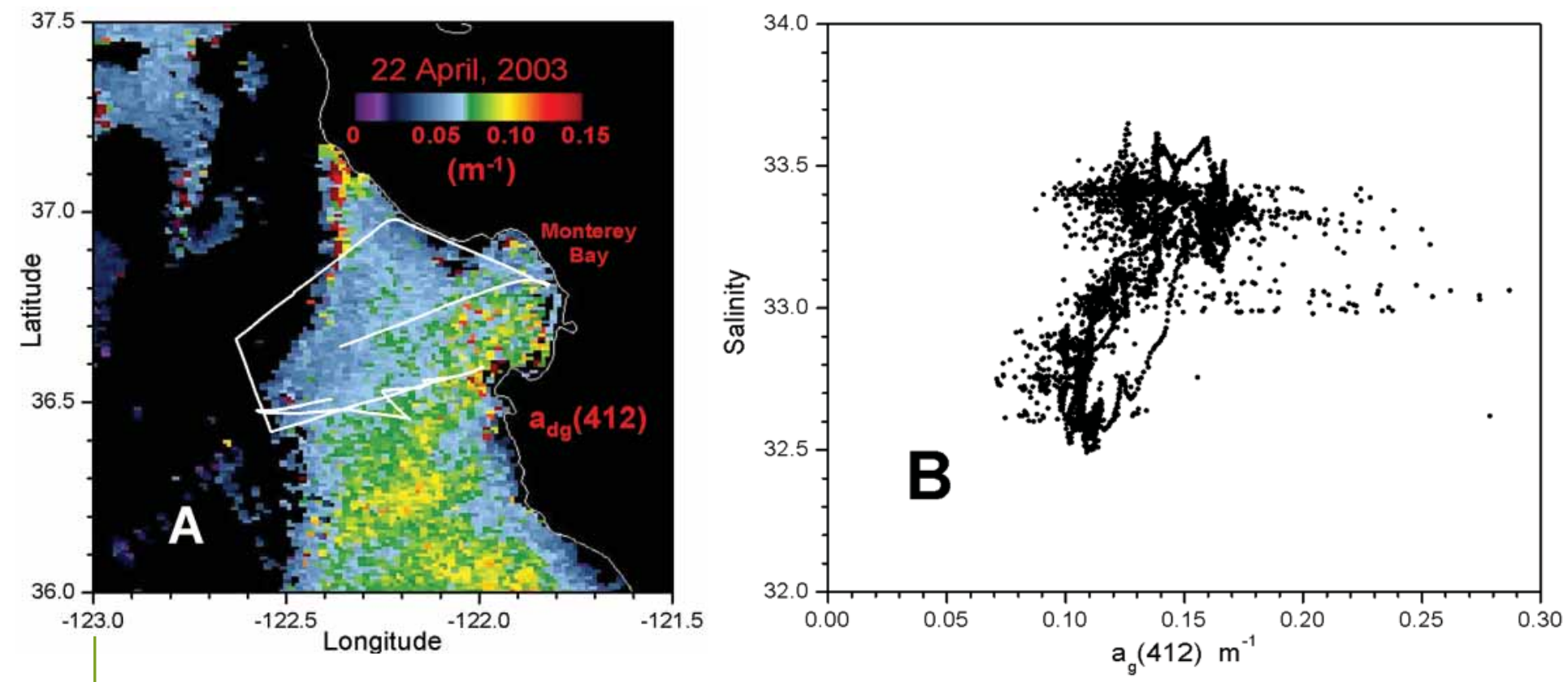

Figure 4. In a few regions, salinity and CDOM can have a positive relationship, with CDOM increasing as salinity increases. This situation can be caused when there is a subsurface source of CDOM and where surface concentrations are low, either because there is sparse freshwater inflow or there is extreme bleaching of CDOM by sunlight. (A) Figure 3 shows data for a Monterey Bay cruise track (white line) overlaid on a SeaWiFS $a_{d g}(412)$ image taken April 22, 2003. Continuous underway flow-through measurements including Conductivity Temperature Depth Sensor (CTD) salinity and CDOM absorption $\left(\mathrm{a}_{\mathrm{g}}\right.$ ) collected with a $0.2 \mu \mathrm{m}$-filtered ac9 instrument. (B) Salinity vs. $\mathrm{a}_{\mathrm{g}}$ at $412 \mathrm{~nm}$ extracted from the underway flow-through data stream. The linear relationship observed in Figures 2 and 3 is now positive rather than negative. Maximum CDOM concentrations are associated with high salinity below the surface, and the linear relationship is caused by upward mixing of these subsurface waters with surface water.

from river runoff or upwelling of deep waters, often is accompanied by input of nutrients that stimulate the growth of phytoplankton. CDOM may decrease the toxicity of heavy metals (Wright and Mason, 1999), especially when other processes enhance formation of metal colloids (Teasdale et al., 2003). Many estuarine and coastal species are known to utilize organic carbon as an energy source through mixotrophic growth; this is particularly apparent in the nutrition of Pfiesteria piscicida (Lewitus et al., 1999), Gymnodinium catenatum (Doblin et al., 1999), and Aureococcus anophagefferens (Lomas et al., 2001), all highly problematic species of phytoplankton associated with harmful blooms.

An interesting example of an apparent correlation between CDOM and the ecology of two different phytoplankton groups was observed off the West Florida Shelf in 1998 (Wood et al, 2001). In this ecosystem, high CDOM concentration is associated with a band of high-turbidity water that extends tens of kilometers from shore. Fluorescence from CDOM is high in these waters and comparison of the distribution of different types of marine picoplankton revealed very

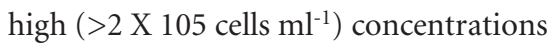
of phycoerythrin (PE)-containing picocyanobacteria in the waters where CDOM was the principal influence on ocean color. In contrast, Prochlorococcus marina, which codominates oligotrophic waters with PE-containing picocyanobacteria were nearly completely absent from the waters where CDOM was abundant. These distribution patterns are consistent with recent genomic evidence that the PE-containing marine picoplankton have a more diverse array of transport systems for the utilization of organic nutrients than Prochlorococcus (Fuhrman, 2003) and suggest that the ability of this group to utilize organic matter as a source of nutrients may be partially responsible for the fact that Synechoccocus often reach their highest abundance in coastal waters. The spectral signature of $\mathrm{PE}$ from these populations is distinctive; data from a wide range of coastal habitats has shown that PE fluorescence spectra obtained from bulk water appears to be diagnostic of optical properties such as the presence of material like CDOM in neritic waters (Figure 5).

One of the challenges for future research on the ecological impact of CDOM is to find a way to use the extensive literature on 
the production and fate of DOM and DOC (Dissolved Organic Carbon) in coastal ecosystems to draw inferences about the specific forms of DOM that are colored. This will be facilitated by experiments like those of Obernosterer and Herndl (2000), which included optical measurements in a study of the response of bacterial communities in the Adriatic and North Sea to photodegradation of humic and non-humic components of DOC. Other studies that will shed light on the ecological impact of CDOM are those that focus on molecules known to contribute to CDOM. Proteins and many amino acids can be detected optically. These molecules are both released from phytoplankton and used as an important nutrient source (Bronk et al., 1994; Palenik and Henson, 1997).

Other components of the pool of CDOM (mycosporine-like amino acids, humic acids) may protect organisms from ultraviolet light, even when released into the water col-

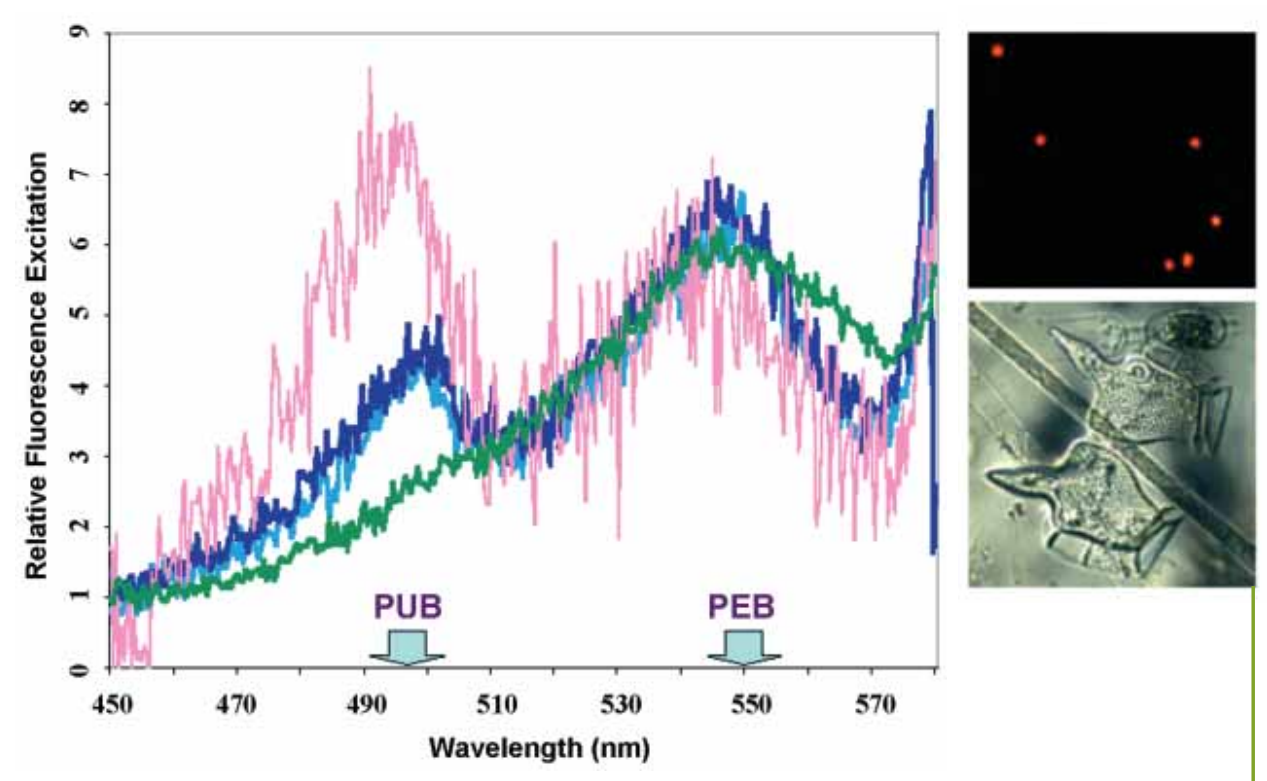

Figure 5. Some phytoplankton are more frequently associated with regions of high CDOM than others. On the West Florida shelf, Dinophysis caudata (lower right) represented $80-100 \%$ of the members of the dinoflagellate family Amphisoleniaceae in high CDOM waters; but only 2-11\% in low CDOM waters where Ornithhocercus spp. were the dominant members of the family. Among the picophytoplankton, phycoerythrin-containing picoplankton in the genus Synechococcus (upper right, cells are about 1 micron in diameter and show up against the dark background because of the autofluorescence from phycoerythrin $[\mathrm{PE}])$ consistently reached their highest concentrations in turbid coastal waters where CDOM concentrations were highest and Prochlorococcus was virtually absent (Wood et al., In Prep.). The spectral form of phycoerythrin associated with PE-containing picocyanobacteria varies depending on the optical environment (Wood et al., 1998) and is correlated with CDOM concentration and source. In the left-hand panel, typical PE spectral signatures from different optical environments are contrasted. Those

associated with upwelling regions where most CDOM is derived from recent phytoplankton growth are shown in blue (c.f. Wood et al., 1999). The spectrum plotted in green is typical of that found in Case 2 regions where there is high input of CDOM from continental sources. This sample was collected in shallow waters on the New Jersey shelf during the HyCODE 2001 experiment. The pink spectrum, typical of the PE that dominates oligotrophic water, is also from HyCODE 2001, but from a "deep blue sea" station where depth exceeded $2000 \mathrm{~m}$. Arrows note the wavelength for maximum absorption by the two chromophores associated with PE, phycourobilin (PUB) and phycoerythrobilin (PEB). As the relative concentration of these two chromophores varies between different PEs, organisms that make the pigment are able to use different portions of the visible spectrum for photosynthesis. Note that the short-wavelength-absorbing chromophore, PUB, is lower, relative to PEB, in the two blue spectra (typical of those collected in Case 1 waters with elevated chlorophyll) than in the pink spectrum from "blue water," and that it is essentially absent in the spectrum from turbid coastal waters where CDOM and chlorophyll remove essentially all the blue light. umn (Vernet and Whitehead, 1996). Finally, many of these colored organic molecules influence the development and growth of animal species. For example, reef corals will incorporate humic acids during calcification (Susic et al., 1991) and the development of sea urchin and crab larvae is enhanced in the presence of humic acids (Forward et al. 2001; Lorenzo et al., 2002).

\section{HOW CAN CDOM BE USED TO} ENHANCE COASTAL MANAGEMENT?

The biogeochemistry of CDOM has profound consequences on the dynamics of coastal ecosystems, and new insights on the links between CDOM and biota are improving our ability to forecast harmful algal blooms and threats to coral reefs. Tracking freshwater circulation in coastal areas enhances tracking of invasive species and other threats to public health. CDOM concentration affects the rate of release of carbon dioxide from terrestrial carbon by limiting or promoting primary productivity. Increased understanding of the role of CDOM will further our ability to manage and protect coastal ecosystems.

Coupling satellite observations with predictive models will provide for better management of coastal areas for mitigation in areas of public health, invasive species, fisheries management, and water resources. CDOM measurements can improve accuracy of carbon and water budgets, leading to enhanced management of freshwater resources and improved carbon cycling models. Coastal regions contribute a significant portion of global ocean production; improving our understanding of how CDOM can influence rates of production as well as species composition will lead to enhanced estimates of new carbon in the ocean. 函 


\section{REFERENCES}

Blough, N.V., and R. Del Vecchio, 2002: Chromophoric DOM in the coastal environment. Pp. 509-546 in Biogeochemistry of Marine Dissolved Organic Matter, D.A. Hansell and C.A. Carlson, eds., Academic Press, Cambridge, MA.

Bronk, D.A., P.A. Glibert, and B.B. Ward, 1994: Nitrogen uptake, dissolved organic nitrogen release, and new production. Science, 265, 1,843-1,846.

Bushaw, K.L., R.G. Zepp, M.A. Tarr, D. Schulz-Jander, R.A. Bourbonniere, R.E. Hodson, W.L. Miller, D.A. Bronk, and M.A. Moran, 1996: Photochemical release of biologically available nitrogen from aquatic dissolved organic matter. Nature, 381, 404-407.

Chen, R.F., and J.L. Bada, 1992: The fluorescence of dissolved organic matter in seawater. Mar. Chem., 37, 191-221.

Coble, P.G., C. Del Castillo, and B. Avril, 1998: Distribution and optical properties of CDOM in the Arabian Sea During the 1995 summer monsoon. Deep Sea Res. II, 45,: 2,195-2,223.

Doblin, M.A., S.I. Blackburn, and G.M. Hallegraeff, 1999: Growth and biomass of the toxic dinoflagellate Gymnodinium catanatum (Graham) by dissolved organic substances. J. Exp. Mar. Biol. Ecol., 236, 33-47.

Forward, R.B., R.A. Tankersley, and D. Rittschoff, 2001: Cues for metamorphosis of brachyuran crabs: An overview. Am. Zool., 41, 1,108-1,122.

Fuhrman, J., 2003: Genome sequences from the sea. $\mathrm{Na}$ ture, 424, 1,001-1,002.

Hu, C., Z.P. Lee, F.E. Muller-Karger, and K.L. Carder, 2003: Application of an optimization algorithm to satellite ocean color imagery: A case study in Southwest Florida coastal waters. SPIE, 4892, 70-79.

Kieber, D.J., and K. Mopper, 1987: Photochemical formation of glyoxylic and pyruvic acids in seawater. Mar. Chem., 21, 135-149.

Lee, Z., K.L., Carder, C.D. Mobley, R.G. Steward, and J.S. Patch, 1999: Hyperspectral remote sensing for shallow waters: 2 . Deriving bottom depths and water properties by optimization. Appl. Opt., 38, 38313843.

Lewitus, A.J., B.M. Willis, K.C. Hayes, J.A.M. Burkholder, H.B. Glasgow, Jr; P.M. Glibert, M.K. Burke, 1999. Mixotrophy and nitrogen uptake by Pfiesteria piscicida (Dinophyceae). J. Phycol., 35(6), suppl., 14301437.
Lomas. M. W., P.M. Glibert, D.A. Clougherty, D.R. Huber, J. Jones, J. Alexander, and E. Harmoto, 2001: Elevated organic nutrient ratios associated with brown tide algal blooms of Aureococcus anophagefferens (Pelagophyceae). J. Pl. Res., 23, 1,339-1,344.

Lorenzo, J.I., O. Nieto, and R. Beiras, 2002: Effect of humic acids on speciation and toxicity of copper to Paracentrotus lividus larvae in seawater. Aquat. Toxicol., 58, 27-41.

Miller, W.L., and M.A. Moran, 1997: Interaction of photochemical and microbial processes in the degradation of refractory dissolved organic matter from a coastal marine environment. Limnol. Oceanogr., 42, 1,317-1,324.

Moran, M.A., and R.G. Zepp, 1997: Role of photoreactions in the formation of biologically labile compounds from dissolved organic matter. Limnol. Oceanogr., 42, 1,307-1,316.

Nelson, N.B., D.A. Siegel, and A.F. Michaels, 1998: Seasonal dynamics of colored dissolved material in the Sargasso Sea. Deep-Sea Res. I, 45, 931-957.

Obernosterer, I., and G.J. Herndel, 2000: Differences in the optical and biological reactivity of humic and nonhumic dissolved organic carbon component in two contrasting coastal marine environments. Limnol. Oceanogr., 45, 1,120-1,129.

Palenik, B., and S.E. Hensen, 1997: The use of amides and other organic nitrogen sources by the phytoplankton Emiliana huxleyi. Limnol. Oceanogr., 42, 1,544-1,551.

Schofield, O., T. Bergmann, M.J. Oliver, A. Irwin, P.W. Bissett, M.A. Moline, and C. Orrico, submitted: Inversion of the Bulk Absorption in the Mid-Atlantic Bight and its Utility for Water Mass Analysis in Optically Complex Coastal Waters, J. Geophys. Res., In Press.

South West Florida Dark Water Observation Group (SWFDOG), 2002: Satellite images track 'black water' event off Florida coast. Eos. AGU Trans., 83(26), $281,285$.

Steinberg, D.K., C.A. Carlson, N.R. Bates, S.A. Goldthwait, L.P. Madin, and A.F. Michaels, 2000: Zooplankton vertical migration and the active transport of dissolved organic and inorganic carbon in the Sargasso. Deep-Sea Res. I, 47, 137-158.

Susic, M., K. Boto, and P. Isdale, 1991: Fluorescence humic acid bands in coral skeletons originate from terrestrial runoff. Mar. Chem., 33, 91-104.
Teasdale, P.R., S.C. Apte, P.W. Ford, G.E. Batley, and L. Keohnken, 2003: Geochemical cycling and speciation of copper in waters and sediments of Macquarie Harobour, Western Tasmania. Est. Coastal and Shelf Sci., 57,475-487.

Twardowski, M.S., and P.L. Donaghay, 2002: Photobleaching of aquatic dissolved materials: Absorption removal, spectral alteration, and their interrelationship. J. Geophys. Res., 107(C8), doi:10.1029/ 1999JC000281.

Vernet, M., and K. Whitehead, 1996: Release of ultraviolet-absorbing compounds by the red-tide dinoflagellate Lingulodinium polyedra. Mar. Biol., 127, 35-44.

Williams, D.E., 2002: Population ecology of bleachingstressed Amphistegina gibbosa in the Florida Keys (1991-1999): Influence of the solar radiation on reefdwelling foraminifera. Ph. D. Dissertation, University of South Florida, St. Petersburg.

Wood, A.M., D.A. Phinney, and C.S. Yentsch, 1998: Water column transparency and the distribution of spectrally distinct forms of phycoerythrin-containing organisms. Marine Ecology Progress Series, 162, 25-31.

Wood, A.M., P.G. Coble, and M. Lipsen, 1999: Fluorescence-based characterization of Synechococcous community structure in the Arabian Sea during the Southwest Monsoon and Fall intermonsoon period. Deep Sea Res. II, 46(8-9), 1,769-1,790.

Wood, A.M., W.K.W. Li, R. Arnone, R. Gould, and S. Lohrenz, 2001: Optical biogeography of Prochlorococcus and Phycoerythin-containing picoplankton on the west Florida shelf. J. Phycol., 37(suppl), 54.

Wright, P., and C.F. Mason, 1999: Spatial and seasonal variation in heavy metals in the sediments and biota of two adjacent estuaries, the Orwell and the Stour, in eastern England. Sc. Tot. Envir., 226, 139-156. 